\title{
EI choque cultural entre los profesores hispanos y el alumnado chino: quejas del alumnado ante el enfoque comunicativo y posibles soluciones
}

\author{
MYRIAM RUEDA ZABALEGUI \\ Universitat Jaume I \\ a1077234@uji.es \\ Alberto Gracia CRESPO \\ albertogracia@ucm.es
}

Universidad Complutense de Madrid

\begin{abstract}
Resumen: El presente trabajo tiene como objetivo mostrar las diferencias culturales que acontecen en el aula de enseñanza de español de diferentes universidades de China. La investigación se centra en la valoración del enfoque comunicativo por parte de los estudiantes, basándonos en un diseño mixto de datos cualitativos y cuantitativos. Los resultados de investigaciones anteriores realizadas a profesores de lengua inglesa muestran que los estudiantes chinos poseen un bajo nivel de adaptación ante los métodos de enseñanza que practican los profesores extranjeros, por este motivo, mediante la presente investigación, tratará de ver si sucede lo mismo con las clases de ELE de los profesores hispanos, para posteriormente aportar soluciones.
\end{abstract}

Palabras clave: Choque cultural, aprendizaje de español, interculturalidad, profesores hispanos, estudiantes chinos, enfoque comunicativo.

The cultural shock between Hispanic teachers and Chinese students: student complaints about Communicative Approach and possible solutions

Abstract: The present work aims to show the cultural differences that occur in the Spanish teaching classroom of different Universities in China. The research focuses on the assessment of the Communicative Approach by the students, based on a mixed design of qualitative and quantitative data. The results of previous research carried out on English language teachers show that Chinese students have a low level of adaptation to the teaching methods practiced by foreign teachers, for this reason, through this research, we will try to see if it happens the same with Spanish teachers' ELE classes, to later provide solutions.

Key words: cultural shock, Spanish language learning, interculturality, Hispanic teachers, Chinese students, Communicative Approach.

\section{Introducción}

El siguiente estudio se basa en experiencias reales, tanto de los autores del artículo como de otros profesores de ELE, en el contexto de la enseñanza del español en China, tratando las quejas más comunes que se reciben en las universidades chinas al final de cada curso. Como señalan los profesores Ewan Dow y Hu Hua Ouyang, a los que seguiremos en su artículo Locales versus visitantes: Las críticas de los estudiantes a los expertos extranjeros en idiomas de las universidades de la República Popular China 
(Dow y Ouyang, 2006) publicado en español en 2006 y compilado en el libro Qué saber para enseñar a estudiantes chinos (Oxman, 2006), existe un desajuste entre la percepción de la calidad de las clases de idiomas extranjeros entre el profesor anglosajón y el alumnado chino, sobre todo con el empleo del enfoque comunicativo, puesto que el profesor extranjero queda satisfecho con sus clases en las que, la respuesta del alumno/a es en apariencia positiva ya que parecen cumplirse los objetivos de aprendizaje propuestos. El problema comienza cuando, una vez terminado el curso, gran parte del alumnado responde negativa o muy negativamente a las encuestas de evaluación del profesorado que se realizan a final de cada semestre. La mayoría de las veces el resultado no solo es inesperado, sino que el profesor no encuentra ninguna respuesta al por qué de esa evaluación negativa, ni al preguntar a los estudiantes, ni al comunicárselo a sus compañeros/as chinos o a sus superiores. Romano y Russo respecto a esta falta de comprensión señalan que «el desconcierto del alumno chino frente al método comunicativo al que no están habituados y que les parece insustancial. No entienden cual es su papel y qué se espera de ellos» (Romano y Russo, 2009: 6). Ante este choque entre expectativas y realidad, se querría aportar en el artículo una enumeración de las quejas más importantes propuestas por estos autores, hacer una encuesta para comprobar si se reflejan en la enseñanza del español y añadir posibles quejas específicas de los encuestados. Con todo ello querríamos proponer también algunas soluciones.

Las principales quejas descritas en el artículo ya mencionado, se refieren tanto a la metodología como al contenido de las clases, y muchas de ellas parecen derivar de la incomprensión entre la cultura del docente y la del alumnado. En cuestión de metodología, muchas veces los alumnos afirman que entienden el enfoque comunicativo como una improvisación constante y como clases poco preparadas. También suelen considerar que el profesor no evalúa seriamente las tareas y que las clases son aburridas. En cuanto al contenido, parece que los alumnos expresan que no aprenden nada o que la enseñanza es inútil, también suelen añadir que los contenidos son triviales y simplistas y que el nivel de enseñanza es de jardín de infantes. Si hablamos de incomprensión cultural, la introducción de elementos de juego, música, u otras actividades fuera de la clase magistral, pueden ser consideradas por parte del alumnado como engañosas, ya que se observan más como generadoras de quanxi (relaciones sociales normalmente interesadas) y no consiguen verlas como actividades educativas. Por otro lado, muchos alumnos localizan un choque cultural y expresan que el profesor no tiene ni idea de a quiénes está enseñando. Por último, encontramos dos quejas comunes que se podría pensar que están entre lo personal y lo cultural; la primera se refiere al acento raro e ininteligible del profesor, mientras que la segunda, está dirigida a su comportamiento, egoísta y de total despreocupación por los problemas y los pedidos de los alumnos. Todo ello puede llevar a la exigencia del reemplazo del profesor, muchas veces pedida de forma inmediata

\section{Marco teórico}

\subsection{Presentación del método comunicativo y breve introducción al estudio de resistencia del alumnado chino a adaptarse a él}

A lo largo de los años, diferentes estudios relativos a la enseñanza de idiomas en China han aportado sus conclusiones sobre la eficiencia del uso del Enfoque Comunicativo 
con los estudiantes locales. Uno de los estudios más notables es el llevado a cabo por Ouyang, llamado Resistance to the Communicative Method of Language with a Progressive Chinese University (Ouyang, 2003), donde trata de explicar la resistencia de los alumnos y profesores chinos a aplicar el enfoque comunicativo en un contexto universitario. Primero de todo querríamos definir lo que entendemos por Enfoque Comunicativo, y para ello hemos tomado la definición de la web del Instituto Cervantes, que lo entiende de esta manera:

El enfoque comunicativo (en inglés, Communicative Approach) se conoce también como enseñanza comunicativa de la lengua (en inglés, Communicative Language Teaching), como enfoque nocional-funcional (en inglés, Notional-functional Approach) o como enfoque funcional (en inglés, Functional Approach). De su apelativo se desprende que con este modelo didáctico se pretende capacitar al aprendiente para una comunicación real -no sólo en la vertiente oral, sino también en la escrita- con otros hablantes de la LE; con este propósito, en el proceso instructivo a menudo se emplean textos, grabaciones y materiales auténticos y se realizan actividades que procuran imitar con fidelidad la realidad de fuera del aula (Instituto Cervantes, 2021).

En el estudio del presente artículo nos vamos a centrar en las quejas respecto al enfoque comunicativo aportadas por en las investigaciones de Ewan Dow y Hu Hua Ouyang, dos de los estudiosos más relevantes sobre China en cuanto a este enfoque se refiere, destacando sobre todo a Hu Hua Ouyang, profesor de la Universidad de Cantón (China). Ambos autores hicieron un estudio de caso poniendo como ejemplo a una profesora estadounidense ficticia que representa el lado extranjero desde las vivencias del propio Ewan Dow y sus compañeros. Tras mostrar de manera narrativa el desarrollo de la relación entre la profesora y el alumnado, localizan una serie de quejas que afectan al intento de esta docente de introducir el enfoque comunicativo en unos alumnos acostumbrados a la educación china tradicional confucianista, más memorística y basada en la repetición. Esto se debe a la relación entre la educación confucianista y los exámenes imperiales que, aunque fueron abolidos en 1905 su influencia sigue resonando en la educación china. Según Jonathan D. Spence, estos exámenes «estaban basados en la memorización y análisis de un grupo de textos prescritos atribuidos al sabio Confucio o a alguno de sus seguidores». (Spence, 1991: 46).

Hay que entender la importancia de Confucio en la cultura china, pues como señala Ann Cheng, no sólo es un filósofo sino una importante base de la cultura china:

Más que un hombre o un pensador, incluso más que una escuela de pensamiento, Confucio representa un autentico fenómeno cultural que se confunde con el destino de toda la civilización china. Este fenómeno, aparecido en el siglo $\mathrm{V}$ a. n. e., se ha mantenido durante 2500 años $\mathrm{y}$ perdura todavía en la actualidad, después de haber sufrido numerosas transformaciones y sobrevivido a muchas vicisitudes (Cheng, 2006: 56).

\subsection{Resistencia al enfoque comunicativo en el entorno ELE en China}

El enfoque comunicativo es tratado por muchos autores generalmente de manera positiva caracterizándose por ser el método más popular ahora mismo, siendo más fácil encontrar artículos sobre sus virtudes que sobre sus posibles problemas o desventajas. Sin embargo, muchas veces estos estudios se realizan en occidente o desde un cierto etnocentrismo occidental y no son tan numerosos los artículos y libros escritos desde el contexto de Asia oriental y desde China en particular, donde el enfoque comunicativo, basado en la acción comunicativa, se enfrenta a un método educativo tradicional de índole confucianista cuyo origen se remonta a hace cientos de años y que ha sufrido su 
propia evolución a lo largo del tiempo. Hay que señalar que esto ni siquiera llegó a cambiar completamente en la época revolucionaria del país, tal y como señala Castillo Ríos: «La educación China no es producto del azar ni fruto espontaneo de la revolución. Ella está vinculada a la historia china y tiene su misma continuidad y secuencia (Castillo Ríos, 1973: 11). En este contexto el enfoque comunicativo es un método novedoso y con un efecto positivo fuera de China (y dentro cuando se sabe adaptar) pero ajeno a la cultura nativa, por lo cual es a la vez codiciado como técnica, pero muchas veces denostado en la práctica como algo ajeno o difícil de comprender. Este problema de la asimilación de la cultura occidental como algo a la vez beneficioso o incluso necesario en lo práctico o técnico pero peligroso para la identidad cultural cruza toda la historia china desde el inicio del contacto con los países occidentales, tal como señalan Dow y Ouyang con respecto a los profesores occidentales y su deseo de implantar este método: «Los chinos quieren la tecnología occidental pero no al precio de perder su cultura y su estabilidad política. Necesitan tecnologías nuevas, pero sin que esto sea un trasplante total de tu modo de enseñar en desmedro del de ellos»». (Dow y Ouyang, 2006: 176).

En cuanto a la enseñanza de ELE, si que hay autores como Eduardo Méndez Marassa que localizan problemas de comprensión cultural que derivan de un contexto cultural y metodológico distinto y que señala en su suplemento en la revista SinoELE Problemas de los estudiantes chinos de español. Ejercicios especificos, en el que comenta un «aparente fallo en las expectativas mutuas», aunque con la esperanza en ese mismo artículo de «encontrar una dirección hacia cómo reducir distancias culturales» (Méndez Marassa, 2005: 2).

Por su lado, Sánchez Griñán pone énfasis en la tradición china de enseñanza aún en uso que ve a la lengua como un objeto de estudio, pero no como una práctica comunicativa, lo que supone un problema para los profesores hispanos:

La enseñanza (pública) de lenguas extranjeras en China está orientada exclusivamente al conocimiento de la L2 como objeto de estudio, dando por sentado que la posibilidad de comunicarse resultará automáticamente como consecuencia del aprendizaje repetitivo de estructuras lingüísticas, conjugaciones y listas de vocabulario. La evaluación basada en exámenes escritos en los que predomina el conocimiento gramatical y léxico, así como la capacidad de traducción, determina la metodología empleada en las aulas y manuales de enseñanza utilizados (Sánchez Griñán, 2017: 214).

A esto hay que añadir las problemáticas culturales que pueden afectar a la relación profesor y alumnos/as y que, como señala He Xiaojing, pueden llegar a inhibir a los alumnos para hablar en clase: «Por los análisis anteriores ya sabemos que muchos alumnos, completamente capacitados para participar en los debates de la clase, no hablan por la modestia». (He, 2008: 17).

No debemos olvidar nunca que, como señala Santos Rovira «la enseñanza de las lenguas extranjeras en China, y en esto el español sigue la misma tendencia que las demás, se ha realizado siempre a través de metodologías que implican un gran esfuerzo por parte de los alumnos/as a través de la memorización y repetición de contenidos y actividades». (Santos Rovira, 2011: 64) 


\section{Metodología}

\subsection{Población y muestra}

La encuesta se realizó a 157 estudiantes del Grado en Lengua y Literatura Española de la Universidad Jinling de Nanjing (China) y de la Universidad de Yangzhou (China), ambas universidades de la provincia de Jiangsu. La franja de edad de estos/as estudiantes está comprendida entre los 18 y los 22 años, desde primero a cuarto de carrera. Aunque normalmente entre el $75 \%$ y el $90 \%$ de las clases de español en China el alumnado es de género femenino, nos ha parecido irrelevante especificarlo, ya que pensamos que las respuestas no variarían teniendo en cuenta este aspecto. Entre los alumnos se encuentran niveles de español muy dispares valorados por el Marco Común Europeo, que varían entre el DELE A1 y el DELE C1. También es necesario puntualizar que la mayor parte de estos/as alumnos han asistido a clases de español con al menos tres profesores hispanos y 20 de estos/as alumnos han estudiado en alguna universidad en países de habla hispana durante al menos un año.

\subsection{Enfoque y diseño}

La investigación está conformada por preguntas mixtas, es decir, 10 encuestas cualitativas con respuestas abiertas y 157 encuestas cualitativas de respuesta cerrada.

El objetivo de las encuestas cualitativas es que el alumnado pueda responder a las preguntas de forma abierta, de modo que podamos encontrar información diferente a la supuesta en las respuestas de la encuesta cuantitativa, así como una mayor profundidad en el análisis de los problemas encontrados.

Las encuestas cuantitativas tienen como objeto saber si la investigación previa realizada por Dow y Ouyang respecto a la ineficiencia del enfoque comunicativo en las clases de lenguas extranjeras en China concuerda con las clases impartidas por los profesores hispanos utilizando el mismo método.

\subsection{Instrumentos}

La parte cuantitativa de la encuesta está conformada por una pregunta con 12 respuestas cerradas en las que los estudiantes pueden seleccionar múltiples respuestas y 1 respuesta abierta en la que pueden escribir otras quejas que no se encuentren en la lista. Esta pregunta trata de reflejar los aspectos negativos del uso del enfoque comunicativo con los estudiantes chinos por parte de los profesores hispanos. La pregunta realizada en dicha encuesta es la siguiente:

1. ¿Qué tipo de quejas tienes sobre los métodos de enseñanza de tus profesores extranjeros? (Elige varias opciones si es necesario):

a) No hay quejas.

b) No aprendí nada.

c) Enseñanza inútil.

d) Contenidos triviales y simplistas.

e) No evalúa seriamente las tareas.

f) Clases poco preparadas. 

g) Improvisación constante.
h) Clases aburridas.
i) Nivel bajo de enseñanza.
j) Contenido o actividades poco serias (cantar, bailar, videos, etc.)
k) Es egoísta y no se preocupa por los problemas de los alumnos.
1) Acento raro e ininteligible.
m) Otras quejas.

En la encuesta cualitativa se llevaron a cabo 10 preguntas cuyos temas engloban aspectos referentes a la metodología, al contenido, a los aspectos culturales, al trato personal profesor - alumno, y otros, donde se deja un apartado donde el estudiante puede escribir aspectos que considere importantes y que no están entre los especificados previamente. Todas estas preguntas se han confeccionado teniendo en cuenta las quejas de los alumnos y los problemas mencionados en el artículo de Dow y Ouyang. Las preguntas son las siguientes:

(1) Las técnicas de enseñanza de los profesores extranjeros, ¿cómo consideras que son? Responde con sinceridad.

(2) ¿Crees que estas técnicas de enseñanza son adecuadas para los alumnos chinos? ¿Sí o no? ¿Por qué?

(3) ¿Crees que los profesores extranjeros deberían utilizar las mismas técnicas de enseñanza que los profesores chinos?

(4) ¿Qué crees que deberían cambiar los profesores extranjeros en sus métodos de enseñanza?

(5) ¿Qué crees que deberían cambiar los profesores chinos en sus métodos de enseñanza?

(6) ¿Crees que las técnicas que utilizan los profesores extranjeros son eficientes a la hora de aprender el español? ¿Qué deberían cambiar o conservar para mantener su eficiencia?

(7) ¿Crees que los profesores extranjeros se adaptan bien a la cultura china dentro del aula? (durante sus clases).

(8) ¿Qué diferencias crees que hay entre el trato de los profesores chinos y los profesores extranjeros con sus alumnos? ¿Qué aspectos positivos y negativos ves en cada uno de ellos?

(9) Cuenta alguna experiencia positiva y negativa con algún profesor extranjero durante su enseñanza (si la has vivido).

(10) Cuenta alguna experiencia positiva y negativa con algún profesor extranjero a nivel personal (si la has vivido).

\section{Procedimiento y análisis de datos}

\subsection{Situación geográfica de los encuestados}

La situación geográfica de las personas encuestadas se recoge en el mapa del mundo llevado a cabo mediante el programa Survey Question Pro, donde se señala en color azul el lugar desde el que se responde a la encuesta, mostrando así la cantidad de 
estudiantes que se han visto expuestos a un menor o mayor número de interacciones con profesores de procedencia hispana.

\subsection{Perspectiva cuantitativa}

Antes de ser enviadas a los alumnos/as, las preguntas cuantitativas pasaron un filtro; primero traduciéndolas al inglés para que pudiesen ser entendidas por los estudiantes con menos nivel de español según el Marco Común Europeo, para posteriormente enviárselas a tres estudiantes diferentes para probar su viabilidad. Una vez pasada la prueba de pilotaje, todas las preguntas fueron introducidas en el programa de Survey Question Pro, cuyo link se envió al resto de alumnos, que dieron su consentimiento para que sus datos fuesen utilizados para un posterior análisis. El tiempo de respuesta a este cuestionario fue de dos minutos aproximadamente.

Todos los datos recopilados en esta encuesta se muestran en la tabla 2, donde se exponen cada una de las respuestas junto a su conteo y porcentaje pertinente, donde es fácil apreciar la cantidad de alumnos que dan valor a un mismo aspecto para posteriormente analizarlo dándole una mayor o menor importancia al problema en cuestión.

\subsection{Perspectiva cualitativa}

La encuesta cualitativa se envió a un total de 10 estudiantes de español. Entre estos alumnos se encontraban 5 con un nivel de español DELE B1, según el Marco Común Europeo, una media de notable en sus calificaciones y un interés no demasiado particular por la lengua y cultura española; otros 3 con un nivel DELE B2, una media de notable alto en sus notas y un interés medio por el idioma y la cultura hispana; finalmente se entrevistó a 2 alumnas con una media de DELE C1, una media de sobresaliente en sus notas de grado y un especial interés por el idioma y la cultura hispana.

Las entrevistas fueron rellenadas por escrito por los mismos estudiantes y recopiladas tal cual se ve en el Anexo adjunto. El tiempo medio estimado que invirtieron los estudiantes rellenando la entrevista fue de aproximadamente media hora. Como la mayoría de los alumnos/as prefirieron mantenerse en el anonimato, aparecerán enumerados como Alumno 1, Alumno 2, etc. Las entrevistas podrán consultarse en los anexos.

\section{Resultados}

\subsection{Resultados geográficos de los encuestados/as}

Como se puede observar en el mapa (Imagen 1) y en la tabla 1, el 94'32\% de los encuestados son estudiantes que se encuentran residiendo en China, por lo tanto, la gran mayoría de ellos sólo han tenido contacto con profesores hispanos que se encuentran residiendo en el país y que, a grandes rasgos, tienen un especial contacto por su cultura. El 2'27\% de los estudiantes están residiendo en Hong Kong, el 1'14\% está en España, otro 1'14\% está en Estados Unidos, el $0^{\prime} 57 \%$ están en Reino Unido y el 0'57\% en 
Tailandia; por lo tanto, estos estudiantes que se encuentran residiendo fuera de China han tenido más contacto con profesores extranjeros, no solo con hispanos.

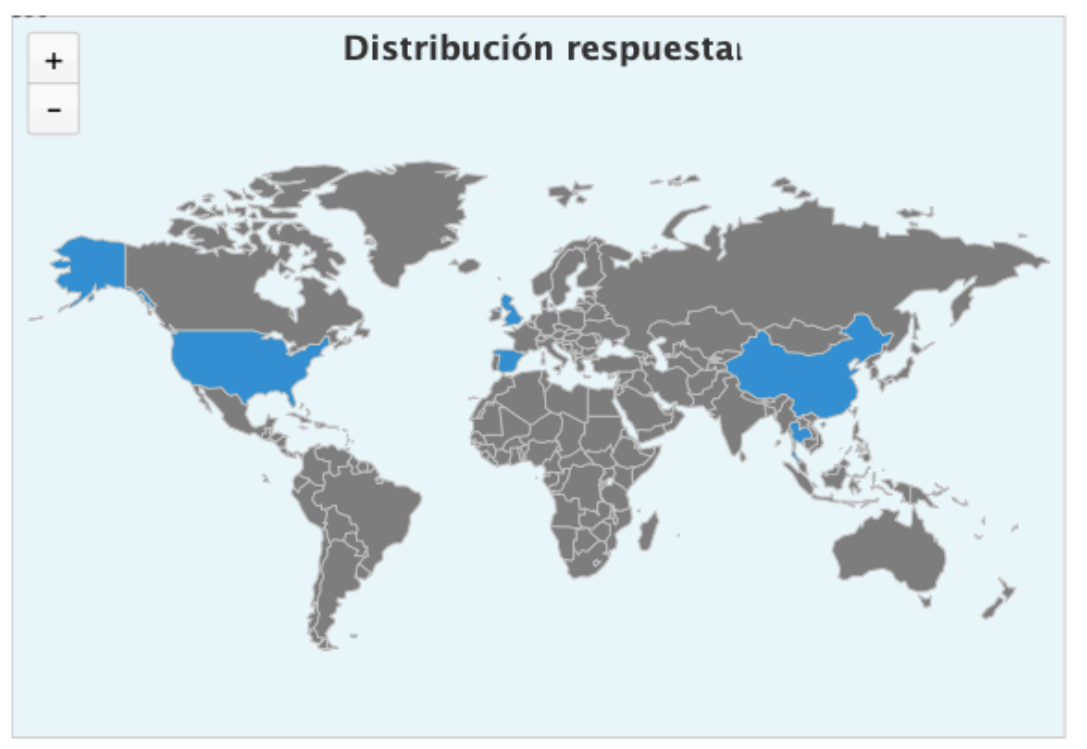

Imagen 1. Mapa mundial del lugar en el que residen los estudiantes encuestados

\begin{tabular}{|c|c|}
\hline PAÍSES & PORCENTAJES \\
\hline China & $94^{\prime} 32 \%$ \\
\hline Hong Kong & $2^{\prime} 27 \%$ \\
\hline Estados Unidos & $1^{\prime} 14 \%$ \\
\hline España & $1^{\prime} 14 \%$ \\
\hline Tailandia & $0^{\prime} 57 \%$ \\
\hline Gran Bretaña & $0^{\prime} 57 \%$ \\
\hline
\end{tabular}

Tabla 1. Situación geográfica en la que se encuentran los alumnos chinos encuestados

\section{Resultados de análisis cuantitativo}

\begin{tabular}{|r|c|c|c|}
\hline & PREGUNTAS & CONTEO & PORCENTAJE \\
\hline $\mathbf{1}$ & Ninguna queja, aprendí mucho & 68 & $43^{\prime} 31 \%$ \\
\hline $\mathbf{2}$ & Enseñanza inútil & 11 & $7^{\prime} 01 \%$ \\
\hline $\mathbf{3}$ & Contenido simplista & 14 & $8^{\prime} 92^{\prime} \%$ \\
\hline $\mathbf{4}$ & No evalúa seriamente las tareas & 8 & $5^{\prime} 1 \%$ \\
\hline $\mathbf{5}$ & Clases poco preparadas & 4 & $2^{\prime} 55 \%$ \\
\hline $\mathbf{6}$ & Improvisación constante & 7 & $4^{\prime} 46 \%$ \\
\hline $\mathbf{7}$ & Clases aburridas & 15 & $9^{\prime} 55^{\prime} \%$ \\
\hline $\mathbf{8}$ & Nivel bajo de enseñanza & 5 & $3^{\prime} 18 \%$ \\
\hline
\end{tabular}




\begin{tabular}{|r|c|c|c|}
\hline $\mathbf{9}$ & Contenido poco serio (cantar, videos, etc.) & 7 & $4^{\prime} 46 \%$ \\
\hline $\mathbf{1 0}$ & Es egoísta, no se preocupa por los problemas de los estudiantes & 4 & $2^{\prime} 55 \%$ \\
\hline $\mathbf{1 1}$ & Acento extraño e ininteligible & 3 & $1^{\prime} 91 \%$ \\
\hline $\mathbf{1 2}$ & No conoce la cultura china & 9 & $5^{\prime} 73 \%$ \\
\hline $\mathbf{1 3}$ & Otras quejas (habla demasiado rápido, aprendizaje repetitivo) & 2 & $1^{\prime} 27 \%$ \\
\hline & TOTAL & $\mathbf{1 5 7}$ & $\mathbf{1 0 0 \%}$ \\
\hline
\end{tabular}

Tabla 2. Resultados del análisis cuantitativo

Como se observa en la tabla 2, gran parte de los estudiantes encuestados (43'1\%) no tienen ninguna queja respecto al enfoque comunicativo utilizado por sus profesores de ELE en China. No obstante, hay un cierto número de estudiantes que sí ve inconvenientes en el uso de este método de enseñanza.

En cuanto a estos contras se refiere, los porcentajes más altos que se encuentran en la gráfica muestran que un $9^{\prime} 55 \%$ opina que las clases son aburridas. En este dato concordamos con las investigaciones de Dow y Ouyang, en el que se afirmaba que las quejas de los estudiantes están centradas en el aburrimiento que suponen para ellos/as las clases, pues un alto número de estudiantes chinos asisten a clases de español por no haber podido entrar en el grado que ellos deseaban; igualmente, cabe señalar que las expectativas de una clase más activa y dinámica son más altas con los profesores extranjeros que con sus profesores chinos.

La siguiente cifra para tener en cuenta es que el $8^{\prime} 92 \%$ piensan que los contenidos son simples. Esta indicación también concuerda con las investigaciones de Dow y Ouyang, ya que en el artículo afirmaba que muchos alumnos consideran que las clases de sus profesores extranjeros son simples en contenido, pues en comparación con la temática aportada por sus profesores chinos en las clases -con listas de vocabulario largas y gramática extensa-, en las clases de los hispanos se trata menos contenido. También es necesario puntualizar que el enfoque comunicativo se centra más en trabajar poco un contenido teórico muy determinado para después ponerlo en práctica con diferentes ejercicios, método que a los estudiantes chinos les parece muy diferente al suyo.

El tercer porcentaje importante es el $7^{\prime} 01 \%$ de los/as estudiantes chinos creen que la enseñanza de los profesores hispanos es inútil, lo cual significa que piensan que su metodología y contenido no les parecen aplicables para ninguna situación lingüística ni son eficientes ni satisfactorios a la hora de aprender el lenguaje.

El cuarto punto que refleja las quejas es que el $5^{\prime} 73 \%$ de los estudiantes creen que los profesores hispanos no se adaptan bien a la cultura china en el aula, o no tienen un conocimiento apropiado de esta cultura a la hora de enseñar. Esto significa que los alumnos chinos tienen otra manera de proceder en las aula muy diferente a la de los profesores hispanos y que puede generar problemas en el desarrollo de la clase y en la comunicación si estos últimos no se adaptan al carácter menos participativo y mucho más tímido de estos alumnos. Además, no conocer las claves o protocolos culturales de comunicación puede llevar a malentendidos y a generar descontento por parte de los/las estudiantes.

El quinto porcentaje es un $5^{\prime} 10 \%$ de los alumnos que opina que las tareas no son evaluadas seriamente, es decir, no creen que los profesores hispanos pongan notas 
equivalentes al esfuerzo invertido o que reflejen el verdadero nivel de los alumnos. También puede referirse a exámenes no adaptados al nivel o notas que les parecen aleatorias. El motivo por el cual las tareas no suelen ser evaluadas al nivel de toda la clase tiene una razón exclusiva, y es que en las clases universitarias de ELE en China suele haber una diferencia muy grande de niveles entre unos alumnos y otros, pues un gran número no tiene demasiado interés en estudiar este idioma $\mathrm{y}$, debido a que en el currículo de este grado se premia más la memorización y el buen comportamiento en clase (Yao, Rueda Zabalegui e Iriarte, 2019: 58), para un gran número de estudiantes es fácil pasar de curso aunque el aspecto práctico del idioma no esté superado adecuadamente.

El sexto porcentaje importante es un 4'46\% que observa la constante improvisación del profesorado hispano como algo negativo. Esto se debe a que los profesores chinos, por regla general, tienen temarios muy cerrados y que los alumnos suelen conocer con antelación, igualmente siguen el libro página por página sin apenas improvisación y siempre con la misma estructura de clase. Las clases de los profesores hispanos, en cambio, les resultan improvisadas debido a su estructura cambiante y muchas veces al no cumplimiento estricto de los temarios.

Un séptimo punto con otro $4 \% 46 \%$ es la incomprensión de los alumnos con respecto a las actividades que complementan el aprendizaje y que pueden consistir en cantar, bailar, poner videos o actividades de corte meramente cultural. Los alumnos pueden llegar a considerarlas una perdida de tiempo, ya que no se está dando contenido serio, a su modo de ver. Una vez más, este tipo de clases dista demasiado de sus costumbres en el estudio, mucho más teóricas y memorísticas.

A continuación, exponemos problemas a los que los alumnos han dado una menor importancia:

- Un 3'18\% señala un bajo nivel de enseñanza.

- Un 2'55\% cree que los profesores hispanos son egoístas y no se preocupan por los problemas de los alumnos.

- Un 2' $55 \%$ opinan que las clases están poco preparadas.

- Un 1'91\% piensa que el acento de los profesores hispanos es extraño o ininteligible.

Aunque son aspectos a tener en cuenta, esta claro que son minoritarios y algunos de ellos derivan de otros problemas más importantes ya señalados y con un porcentaje mayor de queja por parte del alumnado.

\subsection{Resultados del análisis cualitativo}

Tras hacer las preguntas cualitativas descritas en el apartado de metodología se han obtenido en general más comentarios positivos que negativos, siendo la opinión general bastante favorable a los profesores hispanos sobre todo en cuestiones metodológicas y de trato personal, así como de adecuación a la cultura china. Sin embargo, sí que se han detectado bastantes comentarios negativos en cuestiones de contenido, coincidiendo tanto con el artículo de Ouyang y Dow así como con nuestra propia encuesta cuantitativa, y también en la metodología, sobre todo de cara a la estructuración de las 
clases. También se han detectado algunas quejas en cuanto a la adecuación a la cultura china y otras de índole más personal. Ahora se procederá a hacer un análisis de todas las quejas localizadas citando a los propios alumnos. Dividimos el análisis según los temas de metodología, contenido, aspectos culturales, trato personal y otros.

\subsubsection{Resultados del análisis cualitativo en cuanto a metodología}

En cuanto al método de los profesores extranjeros, la Alumna 1 señala que «algunos profesores extranjeros, especialmente los más jóvenes, simplemente utilizan las ventajas de su propio idioma en lugar de técnicas de enseñanza para educar a los estudiantes», dando a entender que fueron contratados por hablar el idioma, pero no por su buen método de enseñanza. El haberse encontrado profesores de español en quienes los alumnos no observan ninguna técnica o sistema reconocible se repite en la Alumna 8, que habla de profesores que dan clase «sin plan de enseñanza, sin sentido». Por otro lado, la Alumna 7 comenta que «los profesores extranjeros, por el contrario, pueden centrarse más en las competencias adquiridas en la práctica, lo que lleva a veces a una falta de enseñanza sistemática». En definitiva, la encuesta saca a relucir que varios de los alumnos ven las clases de los profesores extranjeros como faltas de sistema.

Por otro lado, otras quejas a tener en cuenta con respecto a la metodología tienen que ver con la forma de dirigirse a los alumnos, diciendo la Alumna 2 que «sin la presión, los estudiantes aprenden a su capricho», por lo que podemos entender que los profesores extranjeros le parecen laxos o poco estrictos. La Alumna 3 añade «si yo tuviera que decir uno, es que cuando hacen algunas preguntas a los alumnos chinos, no creen que la mayoría de ellos pueda responder activamente, los profesores tienen que nombrar a uno directamente para responder a las preguntas». Esto se refiere a que la mayoría de los profesores extranjeros pregunta a la clase en general esperando que alguien participe, mientras que es más efectivo preguntar a los alumnos individualmente y de forma directa.

Por último, señalar otras respuestas de alumnos con quejas de otro tipo. La Alumna 8 señala que «los estudiantes chinos son más adecuados para la práctica repetida. Además, siento que aprender un idioma requiere una práctica repetida». Esta respuesta se refiere al método de repetición tradicional chino, al que los alumnos describen como aburrido, pero del que no dudan en cuanto a su eficiencia en al aprendizaje de lenguas. La Alumna 2 en su respuesta piensa que sería mejor combinar ambos métodos, el chino y el extranjero: «Prestar la misma atención a método de traducción gramatical y método audio lingüístico/audiovisual/comunicativo. (combinarlo)». Además, la Alumna 9 señala problemas de adecuación al nivel en las clases de lectura y literatura: «También me encontré con profesores que me dieron clases de literatura y lectura, sinceramente no disfrutaba mucho, creo que hay dos razones, primero el nivel de dificultad de algunos artículos era mucho mayor que mi nivel de español en aquel entonces, muchas palabras no conocidas».

\subsubsection{Resultados del análisis cualitativo en cuanto a contenido}

En cuanto al contenido, las quejas coindicen con el artículo de Dow y Ouyang respecto a que el alumnado considera los contenidos simplistas, o al menos más simples que en las clases de los profesores chinos, tal como señala la Alumna 2: «A decir verdad, en la 
misma hora, en una clase de los profesores chinos, hay más contenido». La Alumna 1 comenta en la misma línea: «a veces siento que algunos profesores extranjeros tienen muy poco contenido en una clase y la producción de conocimientos no es alta». Coincide con la Alumna 8: «Cosa a cambiar: El contenido de la clase es más sustancial». La Alumna 1 lo repite de otra manera: «Pero como dije anteriormente, creo que pueden intentar agregar más contenido al contenido del curso, plantear más problemas a los estudiantes y aumentar su deseo de desafiar». Es interesante como la Alumna 2 señala también una correlación entre clases más prácticas, pero por eso mismo con menor contenido: «Como en la clase hay más tiempo para expresión personal e interacción, entonces nos falta un poco el conocimiento del idioma mismo».

\subsubsection{Resultados del análisis cualitativo en cuanto a aspectos cultarales}

En cuanto a la adaptación de los profesores a la cultura china, el Alumno 6 valora: «bien, pero no suficiente». El caso de estudio en el artículo de Ouyang y Dow se parece a lo que describe la Alumna 1 en cuanto al choque cultural entre alumno y profesor en el aula: «Para ser honesto, creo que la mayoría de los profesores extranjeros no se sienten muy cómodos en la etapa inicial. A veces siempre se preguntan por qué no hay sonido en clase, pero no todos escuchan con atención y todos están en sus propios asuntos. O: ¿Por qué mis alumnos son inexpresivos como si no les agrado mucho, pero se tomaron fotos conmigo después de la clase y publicaron mis fotos en las redes sociales sin mi permiso? Creo que los profesores extranjeros siempre tienen diversas incomodidades, especialmente cuando se convierten por primera vez en profesores extranjeros». Es interesante como la Alumna 2 nos da algunas claves para adaptarse a la cultura china tras comentar que no todos lo hacen y cómo adaptarse implica una predisposición a la cultura, experiencia y ajuste metodológico: «No todos. En mi opinión, para adaptarse bien a la cultura china, se necesita cumplir al menos un punto dentro de los siguientes puntos: 1. (Relativamente) les gusta la cultura china y ya conoce (un poco de) la cultura. 2. Tiene mucha experiencia en la enseñanza con los alumnos chinos. 3. Tienen la conciencia de ajustar los métodos de enseñanza y tienen en cuenta la diferencia entre estudiantes chinos y extranjeros».

Esta falta de adaptación según la Alumna 4 puede llevar a comportamientos indeseados: «Pero algunos no, no entiende la cultura china y a los estudiantes tampoco nos gustan sus comportamientos»». También la mala comprensión de la cultura china y del carácter del alumnado puede llevar a ejercer una presión innecesaria sobre los estudiantes tal como comenta la Alumna 1: «En el lado negativo: algunos estudiantes introvertidos se sentirán presionados. Algunos de mis compañeros me dirán que lo que más temen es asistir a la clase de un profesor extranjero, porque el profesor extranjero tiene que comunicarse con ellos "a la fuerza"». Como vemos, es importante tener conciencia de la interculturalidad, y en esto coincidimos con Hongyi Zhao tal como señala: «tanto los alumnos chinos como los de cualquier país, para estudiar una lengua extranjera no tienen suficiente con aprender los significados literales, sino que se hace necesario del aprendizaje del elemento cultural de la lengua, la interculturalidad». (Zhao, 2016: 25). Esta relación entre lengua y cultura la señala también Trujillo Sáez, que nos indica que realmente esto siempre ha sido así: "es importante señalar que establecer una relación entre enseñanza de la lengua y la cultura no es algo nuevo» (Trujillo Sáez, 2006: 125). 


\subsubsection{Resultados del análisis cualitativo en cuanto a trato personal}

Los alumnos apenas han comentado quejas en el plano personal, quitando alguna mala experiencia aislada como la de la Alumna 2 con un profesor latinoamericano: «Un profesor latinoamericano es descuidado y desdibuja el límite entre el profesor y las compañeras». También la Alumna 4 comenta una mala respuesta por parte de un profesor extranjero ante su acento y pronunciación: «Aunque tuve acento, aunque mi pronunciación no fue muy bien, pienso que por lo menos se pude entender esta frase, pero el profesor no entendió comprenderlo, sino que mostró un expresión muy perplejo, lo que hizo daño a mi dignidad».

\subsubsection{Otros resultados del análisis cualitativo}

Apenas hay otro tipo de quejas. Hay que señalar que la Alumna 4 se sintió molesta por la tardanza de un profesor al responder sus correos electrónicos: «La velocidad de responder el correo es demasiado lento».

\section{Conclusión y posibles soluciones}

\subsection{Conclusiones generales}

En este artículo se ha llegado a la conclusión de que las principales quejas que se recogen en el estudio de Dow y Ouyang sobre los profesores extranjeros, en general, tienen un reflejo importante en la realidad del aula de español y en los profesores hispanos; pues la gran mayoría de profesores extranjeros también utilizan el enfoque comunicativo en sus clases y se encuentran con las mismas incomprensiones y los mismos problemas. Sin embargo, sí se querría señalar en este artículo que las conclusiones de estos autores son demasiado negativas al haber señalado nuestra encuesta que un 43'31\%, una cifra significativa, no tiene ningún problema con las clases de ELE y sus profesores hispanos. Esto puede deberse a que los autores del artículo examinan principalmente a profesores de lengua inglesa con posibles diferencias culturales con respecto a los hispanos. No obstante, esto no significa ni que su estudio no sea importante para nosotros ni que un alto porcentaje de los alumnos, más de la mitad, tenga alguna queja sobre sus profesores hispanos, quejas que se deberían tener en cuenta y que nos deberían llevar a la reflexión.

Tanto en el análisis cuantitativo como el cualitativo ha habido quejas importantes sobre la metodología, tanto a la hora de llamar la atención del alumnado en clase como en su opinión para aprender los conocimientos. Queda claro que el enfoque comunicativo generalmente utilizado por los profesores hispanos les parece interesante para la práctica, pero llegan a calificarlo de aburrido e inútil, a la hora de aprehender los contenidos necesarios. Tampoco comprenden actividades alternativas de índole cultural o no estrictamente lingüísticas (cantar, bailar, etc.). En las entrevistas, aunque algunos alumnos señalan que prefieren el método de los profesores hispanos, sí que notan una desconexión con el método de los profesores chinos viendo este último como más serio, aunque también más aburrido. El enfoque comunicativo también genera presión ante alumnos acostumbrados a un método tradicional chino basado en la repetición y en la memoria, pero no en la participación o en actividades más creativas e improvisadas, además de basadas en situaciones cotidianas y no simplemente seguir un libro de texto. 
En cuanto al contenido, tanto en la encuesta cuantitativa como en las entrevistas a nivel cualitativo, muchos alumnos parecen de acuerdo en que las clases de los profesores hispanos tienen un menor contenido que el de los profesores chinos que enseñan lengua española. También señalan, que el que contenido de los profesores hispanos es simplista o no adaptado al nivel, generalmente a la baja. Es interesante como alguno/a de ellos/as habla de que las prácticas actúan en detrimento del contenido por lo que parece que algunos agradecen el perfil práctico de las clases de los profesores hispanos pese a la reducción de contenido con respecto a las clases de los profesores chinos.

Sobre los aspectos culturales, la mayoría de los alumnos no ve demasiado problema, aunque sí se señalan algunos problemas de adaptación que pueden afectar al desarrollo de la clase y a la relación con los alumnos. En las entrevistas cualitativas se observan expectativas culturales distintas entre profesor y alumno/a además de comportamientos de profesores quizás mal informados que provocan situaciones indeseadas. Como ya señalamos hablando de la metodología, la participación en clase es un asunto importante y esta no debe abordarse sólo desde la perspectiva metodológica, sino que implica cuestiones culturales de cierto calado. Aunque no ha sido señalado en las encuestas, desde nuestra experiencia personal, se han detectado problemas con el concepto chino de mianzi o lian (perder la cara); estos términos los describe también Xiaojing He de esta manera:

Mianzi es la reputación de una persona basada en su estatus en la sociedad (incluyendo el éxito profesional, el cargo, la situación económica, el rol en la interacción, etc.); lian, sin embargo, se refiere al carácter moral públicamente atribuido a la persona (He, 2008:7).

Esto significa que los alumnos tienen miedo a exponerse y cometer errores delante de sus compañeros ante esta pérdida de cara que en un entorno hispano se correspondería con una perdida de dignidad u honor. Esto puede llevarnos a una paradoja también señalada por Xiaojing He: «De aquí deriva una paradoja - a nuestro parecer, también la clave de la falta de competencia comunicativa de determinados alumnos chinos -: no hablan porque quieren hablar bien» (He, 2008:11).

Finalmente, es necesario tener en cuenta la parte de trato personal que está ligada a los aspectos culturales. Si bien en la encuesta cuantitativa sólo un bajo porcentaje de alumnos ha considerado a los profesores hispanos como egoístas, en las entrevistas cualitativas, sí que algunos alumnos han señalado malas experiencias con profesores que consideran que han roto la línea entre su profesión y lo personal, o que han tenido un trato brusco e incluso maleducado. Aunque es claramente minoritario, se quiere dejar constancia de que este problema puede llegar a existir.

\subsection{Posibles soluciones}

En este artículo no solo se quieren presentar las quejas haciendo un mero análisis, sino que se pretende dar algunas soluciones frente a las mismas. Si bien no se van a presentar las soluciones en profundidad, sí se querrían señalar algunas a modo de tentativa hacia una investigación más exhaustiva.

Lo primero sería empezar por un conocimiento, aunque sea general, de la cultura china para saber al país al que se va y el sistema educativo y de valores al que el profesor hispano se enfrenta, ya que la adaptación del enfoque comunicativo, tal como dice Sánchez Griñán, «no puede importarse tal cual de Occidente, sino que debe contar con 
los elementos que conforman la cultura china del aprendizaje» (Sánchez Griñán, 2017: 218). Es importante tener conciencia de la diferencia cultural entre los países, así como tener una mente abierta hacia lo imprevisto. Para ello, aunque parezca evidente, podría ayudar la lectura de libros de historia, pensamiento y cultura china, así como asistir a cursos y conferencias relativos tanto a la China antigua como contemporánea. También es recomendable un conocimiento, aunque sea básico de la lengua, tanto para desenvolverse en la vida cotidiana como por el aprecio que los alumnos tienen al conocimiento de su cultura y de su lengua.

En cuanto a la metodología, es útil el uso del libro de texto al menos como vertebrador o eje de las asignaturas, aunque los alumnos aprecian la creación de material propio si pueden seguirlo. Muchos profesores extranjeros creen que el material original es mejor o más apreciado que seguir un libro, y esto puede ocurrir en otros países, pero en China lleva a la desorientación del alumno que siente que hay una excesiva improvisación y una falta de estructura en el curso. Hay que añadir que por eso mismo el alumno agradece una buena estructuración de las clases, así como la presentación desde el principio de un temario preciso y que este se complete al terminar el curso. Además, si bien las clases de los profesores extranjeros están más centradas en la práctica, no se debe olvidar enseñar algo de teoría gramatical y de contenido léxico para que las clases no les resulten simplistas o carentes de contenido. Por último, si queremos que las actividades no estrictamente lingüísticas del tipo baile, canto u otras actividades más culturales tengan éxito y no sean criticadas, debemos explicar pormenorizadamente su utilidad y su papel en el aprendizaje, ya que, según las entrevistas cualitativas, algunos alumnos, sí que agradecen el aprendizaje por tareas.

Como último punto, hablaremos sobre el contenido. Algo que agradecen los alumnos y que es difícil de llevar a cabo es que las clases con los profesores chinos y con los hispanos se complemente en cuanto a temario, gramática, vocabulario, etc. Esto requiere una comunicación con los profesores chinos que a menudo es complicada o casi imposible, pues como señalan los propios Dow y Ouyang en su artículo, las comunicaciones entre profesores en China muchas veces suceden en un contexto privado en vez de en uno público o académico: «Los chinos [...] intercambian ideas e información y se disputan por la verdad sólo en un contexto privado, de relaciones íntimas o entre personas pertenecientes a un grupo donde no está en juego la reputación de nadie» (Dow y Ouyang, 2006:175-176). Sánchez Griñán, pese a las dificultades descritas, está de acuerdo en la integración de la teoría que dan los chinos con la práctica que dan los profesores hispanos, aunque sea en la medida de lo posible: «Por ejemplo, se podrían poner en práctica en los cursos de comunicación, los conocimientos formales adquiridos en la clase de gramática, o bien reforzar estos en esas clases» (Sánchez Griñán, 2017: 227). Sin embargo, aunque la comunicación con los propios profesores chinos sea complicada, sí que podemos familiarizarnos con los libros que utilizan los profesores chinos: Español moderno, Sueña, Prisma, etc. También es recomendable la comunicación con los alumnos para saber qué temas están aprendiendo con los profesores chinos y adaptarnos a ello. Tampoco hay que dudar en dar listas de vocabulario, ya que los alumnos están acostumbrados a recibir mucho contenido y muchos de ellos lo agradecen. Para terminar, es importante escuchar a los alumnos en cuanto a sus gustos e intereses, así como estar atentos a su posible futuro laboral para elaborar un contenido que les resulte interesante y útil al mismo tiempo. Esto también lo señala He Xiaojing de la siguiente manera: 
En un aula con estudiantes universitarios se puede hablar de música, deportes, literatura, cine, moda, historia e incluso de cotilleos, temas que siempre interesan a los grupos más jóvenes de la sociedad. Sólo sabiendo cuáles son las inquietudes de los alumnos, es posible que el profesor pueda motivarlos con eficacia en las actividades realizadas en el aula. Para esto hay que efectuar análisis previos sobre los intereses y las necesidades de los alumnos (He, 2008:17).

\section{Bibliografía}

Aristu Allero, Ana. 2014. Adecuación de la metodología de enseñanza de español a estudiantes chinos a través del portafolio del profesor y la reflexión docente. Estudio de caso en una escuela de idiomas de Barcelona. Barcelona: Universitat de Barcelona.

CASTILlo Ríos, Carlos. 1973. La educación en China. Una pedagogía revolucionaria. Buenos Aires: Búsqueda.

CHENG, Anne. 2006. Historia del pensamiento chino. Barcelona: Bellaterra.

Dow, Ewan. Y OUYANG, Hu Hua. 2006. «Locales versus visitantes: Las críticas de los estudiantes a los expertos extranjeros en idiomas de las universidades de la República Popular China». En C. Oxman (ed.), Qué saber para enseñar a estudiantes chinos. Buenos Aires: Parolas language, 161-178.

HE, Xiaojing. 2008: El silencio y la imagen china en el aula de ELE. Recuperado el 10/07/2021, de: www.linred.es/articulos_pdf/LR_articulo_31102008.pdf

InSTITUTO Cervantes, 2021. Diccionario de términos clave de ELE. Recuperado el 5/07/2021,

de:https://cvc.cervantes.es/ensenanza/biblioteca_ele/diccio_ele/diccionario/enfoquecom unicativo.htm

MendeZ Marassa, Eduardo. 2009. «Problemas de los estudiantes chinos de español. Ejercicios específicos». Suplementos Revista SinoELE, 1, 1-99.

OuYANG, Hu Hua. 2003: «Resistance to the Communicative Method of Language with a Progressive Chinese University. Anthropology and Wold Culture Theory». En Anderson-Levitt K. M. (ed.) Local Meanings, Global Schooling. Los Ángeles: Palgrave, 122-145.

ROMANO, Evelia y RUSSO, Alejandra. 2009: «Ideas y prácticas para una comunicación intercultural efectiva con estudiantes chinos de español». I Congreso de enseñanza de español como lengua segunda y extranjera, Universidad del Salvador, 1-10.

SÁNCHEZ GRIÑÁN, Alberto José. 2017: «Reconciliación metodológica e intercultural: Posibilidades de la enseñanza comunicativa de lenguas en China». En C. Oxman (ed.), Qué saber para enseñar a estudiantes chinos. Buenos Aires: Parolas language, 209-259.

SANTos Rovira, José María. 2011. La enseñanza del español en China: Historia, desarrollo y situación actual. Lugo: Axac.

SPENCE, Jonathan Dermot. 1991. The search for modern china. Londres: Norton.

TRUjILlo SÁEZ, Fernando. 2008. Cultura, comunicación y lenguaje. Reflexiones para la enseñanza de la lengua en contextos multiculturales. Granada: Octaedro.

Feng, Yao, Rueda Zabalegui, Myriam e Iriarte, Fernando. 2019. «Estrategias de aprendizaje y su relación con el rendimiento académico (gramática, lectura y audición) 
de los estudiantes chinos que aprenden español como lengua extranjera», SinoELE, 18, 56-70.

ZHAO, Hongyi. 2016: «La comunicación intercultural en la enseñanza del español como lengua extranjera para sinohablantes: análisis de diferencias culturales y propuestas de mejora». Suplementos SinoELE, 15, 1-26. 
ALUMNA 1

\section{PREGUNTAS SOBRE LAS TÉCNICAS DE ENSEÑANZA DE LOS PROFESORES EXTRANJEROS DE ESPAÑOL EN CHINA}

- $\quad$ Responde sinceramente a las siguientes preguntas teniendo en cuenta las técnicas de enseñanza de todos los profesores extranjeros de español que hayas tenido a lo largo de tu vida estudiantil.

- En el caso de tener que referirte a alguno de los profesores de español en concreto, lo mantendremos de manera anónima no diciendo ni tu nombre ni el del profesor.

- ¡Gracias por tu ayuda!

1. Las técnicas de enseñanza de los profesores extranjeros, ¿cómo consideras que son? Responde con sinceridad.

Personalmente, creo que las técnicas de enseñanza de los profesores extranjeros con las que me he encontrado son mixtas. Para algunos profesores extranjeros, obviamente se puede sentir su gran entusiasmo por la enseñanza y algunos métodos de enseñanza especiales, que benefician mucho a los estudiantes. Pero algunos profesores extranjeros, especialmente los más jóvenes, simplemente utilizan las ventajas de su propio idioma en lugar de técnicas de enseñanza para educar a los estudiantes.

我个人认为我接触到的外教的教学技巧是好坏参半的, 有些外教你很明显能感受 到他浓厚的教学热情和特殊的一些教学方法, 这使学生受益匪浅。但有些外教, 特别是年龄较为轻的, 很多只是单纯的运用自己的语言优势而不是教学技巧在教 育学生。

2. ¿Crees que estas técnicas de enseñanza son adecuadas para los alumnos chinos? ¿Sí o no? ¿Por qué?

Sí, Porque desde mi experiencia personal, estas habilidades de enseñanza son útiles para la eficiencia de mi aprendizaje y, al mismo tiempo, también aumentan mi interés por aprender. 
是的, 因为就我个人的体验来看这些教学技巧都对我的学习效率有帮助, 同时它 还提高了我的学习兴趣。

3. ¿Crees que los profesores extranjeros deberían utilizar las mismas técnicas de enseñanza que los profesores chinos?

No, porque necesitan establecer un estilo diferente al de los profesores chinos. Al mismo tiempo, debido a que el enfoque de los profesores extranjeros suele ser diferente al de los profesores chinos, por ejemplo, los profesores extranjeros enseñan conversaciones diarias y los profesores chinos enseñan patrones de gramática y oraciones. No pueden utilizar las mismas habilidades de enseñanza para completar la enseñanza.

不应该，因为他们需要和中国老师建立不同的风格。同时，由于外教教学的侧重 点和中国老师大都时候会有不同，比如外教教日常对话用语，中国老师教语法、 句式，他们不能用同样的教学技巧完成教学。

4. ¿Qué crees que deberían cambiar los profesores extranjeros en sus métodos de enseñanza?

A veces siento que algunos profesores extranjeros tienen muy poco contenido en una clase y la producción de conocimientos no es alta.

有些时候我总觉得有些外教一堂课的内容设置的很少, 知识的输出量不高。

5. ¿Qué crees que deberían cambiar los profesores chinos en sus métodos de enseñanza?

希望他们能更多注意和学生的互动, 同时不要总是让我们读课文了...... Espero que puedan prestar más atención a la interacción con los estudiantes y que no siempre nos dejen leer el texto...

6. ¿Crees que las técnicas que utilizan los profesores extranjeros son eficientes a la hora de aprender el español? ¿Qué deberían cambiar o conservar para mantener su eficiencia?

La mayoría son eficaces. Pero como dije anteriormente, creo que pueden intentar agregar más contenido al contenido del curso, plantear más problemas a los estudiantes y aumentar su deseo de desafiar.

大多数是有效的。但正如我上面说的, 我想他们可以试着在课程内容多加一些内 容, 给学生多提一些难题, 增加他们的挑战欲。

7. ¿Crees que los profesores extranjeros se adaptan bien a la cultura china dentro del aula? (durante sus clases). 
Para ser honesto, creo que la mayoría de los profesores extranjeros no se sienten muy cómodos en la etapa inicial. A veces siempre se preguntan por qué no hay sonido en clase, pero no todos escuchan con atención y todos están en sus propios asuntos. O: ¿Por qué mis alumnos son inexpresivos como si no les agrado mucho, pero se tomaron fotos conmigo después de la clase y publicaron mis fotos en las redes sociales sin mi permiso?

Creo que los profesores extranjeros siempre tienen diversas incomodidades, especialmente cuando se convierten por primera vez en profesores extranjeros.

说实话我认为大多数外教初期都不是很适应。有时候他们总是会疑惑为什么上课 的时候鸦雀无声但大家又没有在认真听讲都在各自开小差。或者是：为什么我的 学生们在可是面无表情好像不太喜欢我的样子，但课后却和我合照未经我允许将 我的照片发到社交媒体上。

我想外教总有各种各样的不适应, 特别是他们刚成为外教的时候。

8. ¿Qué diferencias crees que hay entre el trato de los profesores chinos y los profesores extranjeros con sus alumnos? ¿Qué aspectos positivos y negativos ves en cada uno de ellos?

Creo que los profesores extranjeros estarán más preocupados por el dominio del conocimiento de cada alumno, mientras que los profesores chinos son en su mayoría los únicos responsables de la clase debido a la gran cantidad de alumnos. Si los alumnos tienen alguna duda, se la preguntarán al profesor ellos mismos.

Los aspectos positivos y negativos de esto son:

En el lado positivo: la preocupación de los profesores extranjeros a veces puede convertirse en la motivación para que los estudiantes aprendan bien el idioma. Muchos estudiantes que están dispuestos a comunicarse se llevarán bien con los profesores extranjeros y sienten que la comunicación no estará tan llena de distancia como la Profesor de chino. Índice de distancia de potencia (PDI : power distance index ) Estará más cerca.

En el lado negativo: algunos estudiantes introvertidos se sentirán presionados. Algunos de mis compañeros me dirán que lo que más temen es asistir a la clase de un profesor extranjero, porque el profesor extranjero tiene que comunicarse con ellos"a la fuerza".

我认为外教们会更关心每个学生的知识掌握情况，而中国老师由于学生人数众 多，大多只负责把课上了，如果同学有疑问他们自己去请教老师。 这导致的积极和消极的一面分别是：

积极的一面：外教的关心有时候会成为学生学好语言的动力, 很多乐于交流的学 生会和外教相处愉快并且觉得沟通会不像对中国老师那样充满距离感, 权利距离 PDI (power distance index) 会近一些。

消极的一面：一些内向的学生会觉得有压力。我有些同学会和我说他们最怕的事 就是上外教的课，因为外教要强行和他们沟通。

\section{Cuenta alguna experiencia positiva y negativa con algún profesor extranjero} durante su enseñanza (si la has vivido). 
Experiencia positiva :

Mi tutor de tesis de pregrado, Jesús, me dejó una profunda impresión. Cuando me decidí por el tema al principio, elogió mi elección y me dio muchos recursos. Esto es realmente genial comparado con la indiferencia de los profesores chinos. Más tarde, durante el período del covid-19, no supe cómo escribir el esquema de la tesis, él me llamó por voz y me enseñó verbalmente durante unas 2 horas, y finalmente me aclaré. Puedo decir que ningún profesor de chino tiene tal sentido de responsabilidad con los estudiantes. Más tarde, al final de la defensa de la tesis, Jesús nos dio un mensaje y nos elogió. Todavía recuerdo su mensaje y estoy muy conmovido. Me siento muy afortunado de tener un profesor extranjero como este. Adjuntaré este mensaje a continuación, recuerde mosaico.

我的本科论文导师 Jesus 给我留下了很深的印象。在我初期决定题目的时候他第 一时间对我的选题表示赞许并且给了我很多可以用的资源。这和中国老师的冷漠 相比真的太好了。后来在 covid-19 期间，我不知道怎么列论文大纲，他给我语音 电话, 口头教学了我约 2 个小时, 我终于豁然开朗。我可以说没有一个中国老师 会如此对学生有责任感, 后来, 在论文答辩结束的时候, Jesus 还给我们留言, 夸 奖我们。他的那段留言我至今回忆起来我都非常感动。我为拥有这样的外教而感 到非常幸运。我会把这段留言附在下面, 记得打马赛克。

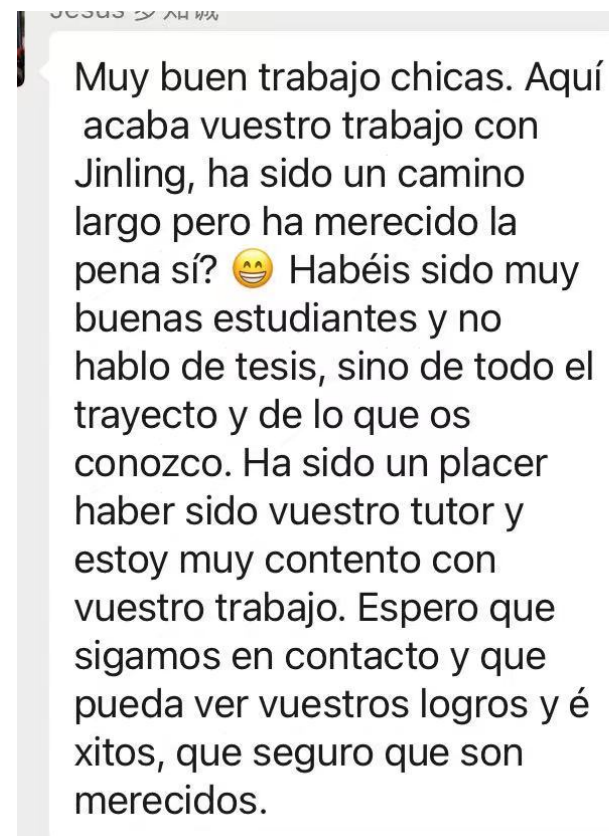

Experiencia de aprendizaje negativa: hay un profesor extranjero, no recuerdo el nombre, la clase está leyendo PPT por completo, y luego no importa lo que el estudiante esté haciendo bien o mal, obtendrá sus buenos puntajes. Pensó que se estaba beneficiando mutuamente con los estudiantes, pero pudimos sentir su falta de sinceridad. 消极的学习经历：有位外教, 我不记得名字了, 上课完全就是在读 PPT, 然后不 管是学生学得好或差都给学生一个不错的分数。他以为是在和学生互惠互利, 但 我们能感受到他的不真诚。 
10. Cuenta alguna experiencia positiva y negativa con algún profesor extranjero a nivel personal (si la has vivido).

Experiencia positiva : Todavía recuerdo una vez cuando mi profesor extranjero y mi amigo me pidió que ir al hospital para mascotas para comprobar el gato. La noche anterior, rompí con mi novio y yo estaba en un mal estado de ánimo y los ojos enrojecidos por el llanto. El profesor extranjero me consoló en la impermanencia del mundo, mirando hacia adelante, estaba muy conmovido y mi estado de ánimo mejoró mucho.

No experiencia negativa.

还记得有一次我的外教老师同时也是我的朋友约我一起去宠物医院给猫咪做检 查, 前一天晚上我刚和男朋友分手心情低落, 眼睛哭的通红。我感到非常感动， 心情也变好了很多。

\section{ALUMNA 2}

\section{PREGUNTAS SOBRE LAS TÉCNICAS DE ENSEÑANZA DE LOS PROFESORES EXTRANJEROS DE ESPAÑOL EN CHINA}

- $\quad$ Responde sinceramente a las siguientes preguntas teniendo en cuenta las técnicas de enseñanza de todos los profesores extranjeros de español que hayas tenido a lo largo de tu vida estudiantil.

- En el caso de tener que referirte a alguno de los profesores de español en concreto, lo mantendremos de manera anónima no diciendo ni tu nombre ni el del profesor.

- ¡Gracias por tu ayuda!

1. Las técnicas de enseñanza de los profesores extranjeros, ¿cómo consideras que son? Responde con sinceridad.

Considero que son muy occidentales (tienen un estilo o sentido fuerte)

Se destaca el pensamiento crítico, la interacción y la libertad de explicarse.

Tienen mucha diversidad, que no solo se enfoca al mismo método de enseñanza.

Son más interesantes que las de los profesores chinos.

2. ¿Crees que estas técnicas de enseñanza son adecuadas para los alumnos chinos? ¿Sí o no? ¿Por qué?

Sí, porque constantemente los profesores chinos prestan más atención al enfoque tradicional y el método de traducción gramatical. De hecho esto es la característica 
china en toda la enseñanza, no solo para idiomas. Pero el idioma es una herramiente para comunicarse, entonces, el método audio lingüístico/audiovisual/comunicativo también es muy importante. Pero ellos o el libro de texto no nos ofrece suficiente práctica.

3. ¿Crees que los profesores extranjeros deberían utilizar las mismas técnicas de enseñanza que los profesores chinos?

No, porque justamente las técnicas de los profesores extranjeros y las de los profesores chinos pueden ser complementarias, como dos media naranja. Ambas partes tienen sus ventajas y desventajas. (combinarlo)

4. ¿Qué crees que deberían cambiar los profesores extranjeros en sus métodos de enseñanza?

Prestar la misma atención a método de traducción gramatical y método audio lingüístico/audiovisual/comunicativo. (combinarlo)

5. ¿Qué crees que deberían cambiar los profesores chinos en sus métodos de enseñanza?

Prestar la misma atención a método de traducción gramatical y método audio lingüístico/audiovisual/comunicativo.

6. ¿Crees que las técnicas que utilizan los profesores extranjeros son eficientes a la hora de aprender el español? ¿Qué deberían cambiar o conservar para mantener su eficiencia?

Más o menos, $80 \%$

A decir verdad, en la misma hora, en una clase de los profesores chinos, hay más contenido. Pero los estudiantes pueden practicar mucho la audición y la expresión oral en la clase.

Conservar las actividades del enfoque comunicativo e intentar añadir un poco más del idioma mismo. (vocabulario, léxico, gramática)

Para ahorrar el tiempo, a lo mejor pueden difundir las preguntas, la lista de vocabulario o las frases que van a enseñar en la clase a sus alumnos con anticipación para que las conozcan mejor.

7. ¿Crees que los profesores extranjeros se adaptan bien a la cultura china dentro del aula? (durante sus clases).

No todos. En mi opinión, para adaptarse bien a la cultura china, se necesita cumplir al menos un punto dentro de los siguientes puntos: 1. (Relativamente) les gusta la cultura china y ya conoce (un poco de) la cultura. 2 . Tiene mucha experiencia en la enseñanza con los alumnos chinos. 3 . Tienen la conciencia de ajustar los métodos de 
enseñanza y tienen en cuenta la diferencia entre estudiantes chinos y extranjeros. Según mi experiencia estudiantil, en la facultad de educación de las universidades extranjeras, incluso en la carrera de formación de profesores de ELE, se enseña más el conocimiento sobre la educación extranjera. Por eso, se exige un alto nivel de experiencia o base oriental, o sea, un largo tiempo para la formación personal, entonces, solo pocos profesores extranjeros pueden llegar a este nivel.

8. ¿Qué diferencias crees que hay entre el trato de los profesores chinos y los profesores extranjeros con sus alumnos? ¿Qué aspectos positivos y negativos ves en cada uno de ellos?

Generalmente, los profesores chinos son más estrictos, serios o fríos en la clase. Nos indica directamente nuestros errores (de manera menos suave) Además, si no hemos puesto suficientes esfuerzos al estudio, por ejemplo, no recordamos la conjugación de unas palabras irregulares aunque la profesora ya las menciona muchas veces en la clase, o podemos escribir de memoria los textos, el vocabulario o el léxico en clase, o no sacamos buenas notas en el examen parcial o final, nos crítica con palabras "fuertes o agudas."

En las clases de profesores extranjeros, el ambiente es más suave y estamos más relajados. Tenemos menos presión y más libertad de expresarnos, o "producir sonidos". En las clases de profesores chinos, estamos totalmente atentas y frecuentemente mantenemos el silencio. Yo no estaba tan preocupada de cometer errores en las clases de profesores extranjeros, y me sentía menos embaraza si cometí un error. Porque para los profesores chinos, los errores repetidos valoran mucho y significan mucho (falta atención)

los profesores chinos: aspectos positivos: 1. Recordamos firmemente el conocimiento básico del español y lo dominamos muy bien.

2. El ambiente de la clase es mejor. Nadie puede dormir o estar distraído en la clase.

aspectos negativos: 1. Los estudiantes sienten más presión psicológica.

2 , Tienen menos interés e iniciativa de las clases.

los profesores extranjeros: aspectos positivos: 1. La mayoría de los estudiante se sienten más felices en la clase, al menos yo.

2, Los estudiantes pueden desarrollar más competencia comunicativa.

aspectos negativos: 1 . Sin la presión, los estudiantes aprenden a su capricho.

2, Como en la clase hay más tiempo para expresión personal e interacción, entonces nos falta un poco el conocimiento del idioma mismo.

9. Cuenta alguna experiencia positiva y negativa con algún profesor extranjero durante su enseñanza (si la has vivido).

Me parece que toda mi experiencia era positiva y nunca me sentía mal en las clases. 
10. Cuenta alguna experiencia positiva y negativa con algún profesor extranjero a nivel personal (si la has vivido).

Experiencia positiva: Con los profesores extranjeros organizamos las actividades interesantes en la asociación estudiantil y el feriado de la cultura hispanohablante de la facultad. Y unas veces salimos a comer afuera juntos. También hemos organizado algunas reuniones. Los estudiantes practicamos el español y conocemos más la cultura hispanohablante. Los profesores extranjeros conocen más la vida cotidiana en China.

Experiencia negativa: Para unos profesores latinoamericanos, el tema de los Estados Unidos y España es un poco sensible por la historia.

Un profesor latinoamericano es descuidado y desdibuja el límite entre el profesor y las compañeras.

\section{ALUMNA 3}

\section{PREGUNTAS SOBRE LAS TÉCNICAS DE ENSEÑANZA DE LOS PROFESORES EXTRANJEROS DE ESPAÑOL EN CHINA}

- $\quad$ Responde sinceramente a las siguientes preguntas teniendo en cuenta las técnicas de enseñanza de todos los profesores extranjeros de español que hayas tenido a lo largo de tu vida estudiantil.

- En el caso de tener que referirte a alguno de los profesores de español en concreto, lo mantendremos de manera anónima no diciendo ni tu nombre ni el del profesor.

- ¡Gracias por tu ayuda!

1. Las técnicas de enseñanza de los profesores extranjeros, ¿cómo consideras que son? Responde con sinceridad.

Por ejemplo, explicar las informaciones directamente, hacer las preguntas, hacer a alumnos debatir, leer las lecturas, presentar algo directamente, usar PPT.

2. ¿Crees que estas técnicas de enseñanza son adecuadas para los alumnos chinos? ¿Sí o no? ¿Por qué?

Para los alumnos avanzados, todas son adecuadas. Pero para los alumnos que acaban de empezar a estudiar el español, solo explicar con las frases sencillas, hacer las preguntas básicas, usar PPT con algunas explicaciones chinas y presentar algo directamente son adecuadas. 
3. ¿Crees que los profesores extranjeros deberían utilizar las mismas técnicas de enseñanza que los profesores chinos?

No. Porque los profesores chinos y extranjeros tienen sus propias ventajas, los chinos son más adecuados para la explicación y los extranjeros para la práctica, como las audiciones, comunicaciones etc. Creo que los profesores extranjeros poseen las ventajas, por ejemplo, la entonación de la lengua y cuando hablan, la velocidad es diferente de la que los chinos hablan. Por eso, para los profesores extranjeros, creo que ellos tienen que hablar más con los estudiantes para que puedan ajustarse mejor a los hispanohablantes nativos.

4. ¿Qué crees que deberían cambiar los profesores extranjeros en sus métodos de enseñanza?

En realidad, todos mis profesores extranjeros enseñan muy bien y no puedo proponer algo... Si yo tuviera que decir uno, es que cuando hacen algunas preguntas a los alumnos chinos, no creen que la mayoría de ellos pueda responder activamente, los profesores tienen que nombrar a uno directamente para responder a las preguntas.

5. ¿Qué crees que deberían cambiar los profesores chinos en sus métodos de enseñanza?

No se centran mucho en los detalles y ejercicios porque aprender la lengua es para usar, no es para el examen.(Aunque el examen como EEE o Dele todavía es muy muy importante!)

6. ¿Crees que las técnicas que utilizan los profesores extranjeros son eficientes a la hora de aprender el español? ¿Qué deberían cambiar o conservar para mantener su eficiencia?

Además de escuchar las audiciones y radios, me parece que ver las series y explicar algunos usos o palabras que nunca aparecen en los libros es una manera muy eficiente.

7. ¿Crees que los profesores extranjeros se adaptan bien a la cultura china dentro del aula? (durante sus clases).

Sí, porque todos mis profesores son muy puntuales.(No sé si es la verdad, dicen que en España o América Latina, siempre los profesores llegan a la clase tarde jaja) Y también mis profesores pueden hablar con nosotros sobre la gastronomía china.

8. ¿Qué diferencias crees que hay entre el trato de los profesores chinos y los profesores extranjeros con sus alumnos? ¿Qué aspectos positivos y negativos ves en cada uno de ellos?

En realidad, no hay diferencias obvias. Los profesores extranjeros nos tratan con más entusiasmo y menos estrictez. No hay aspectos negativos (solo para los alumnos que no quieren estudiar, para ellos, la clase de los extranjeros es más fácil de divertirse) los positivos son que a los alumnos les gusta más tener las clases de profesores extranjeros.

9. Cuenta alguna experiencia positiva y negativa con algún profesor extranjero durante su enseñanza (si la has vivido).

No hay la experiencia negativa. La positiva es ser amiga con ellos, así que me han dado mucha ayuda en mi estudio, porque siempre les pregunto algunos usos o frases. Y esto me hace más bravo de charlar con los extranjeros. 
10. Cuenta alguna experiencia positiva y negativa con algún profesor extranjero a nivel personal (si la has vivido).

No hay la experiencia negativa. La positiva es ser amiga con ellos, así que me han dado mucha ayuda en mi estudio, porque siempre les pregunto algunos usos o frases. Y esto me hace más bravo de charlar con los extranjeros.

\section{ALUMNA 4}

\section{PREGUNTAS SOBRE LAS TÉCNICAS DE ENSEÑANZA DE LOS PROFESORES EXTRANJEROS DE ESPAÑOL EN CHINA}

- $\quad$ Responde sinceramente a las siguientes preguntas teniendo en cuenta las técnicas de enseñanza de todos los profesores extranjeros de español que hayas tenido a lo largo de tu vida estudiantil.

- En el caso de tener que referirte a alguno de los profesores de español en concreto, lo mantendremos de manera anónima no diciendo ni tu nombre ni el del profesor.

- ¡Gracias por tu ayuda!

1. Las técnicas de enseñanza de los profesores extranjeros, ¿cómo consideras que son? Responde con sinceridad.

Es más libre. Es importante ser autodidacta.

2. ¿Crees que estas técnicas de enseñanza son adecuadas para los alumnos chinos? ¿Sí o no? ¿Por qué?

No. En Santiago de Compostela, enseñan en el gallego.

3. ¿Crees que los profesores extranjeros deberían utilizar las mismas técnicas de enseñanza que los profesores chinos?

Creo que deben los alumnos aprender a adecuarse.

4. ¿Qué crees que deberían cambiar los profesores extranjeros en sus métodos de enseñanza?

Para mí, me gustaría que podamos ver más películas en clase.

5. ¿Qué crees que deberían cambiar los profesores chinos en sus métodos de enseñanza?

No puedo recordar en detalle...

6. ¿Crees que las técnicas que utilizan los profesores extranjeros son eficientes a la hora de aprender el español? ¿Qué deberían cambiar o conservar para mantener su eficiencia? 
Sí, perfecto.

7. ¿Crees que los profesores extranjeros se adaptan bien a la cultura china dentro del aula? (durante sus clases).

Sí, siempre dicen "China" jajaja.

8. ¿Qué diferencias crees que hay entre el trato de los profesores chinos y los profesores extranjeros con sus alumnos? ¿Qué aspectos positivos y negativos ves en cada uno de ellos?

Cuando estamos en España, parecemos más tranquios que los extranjeros. Por eso, algunos profesores aquí suelen hablar menos con nosotros. En China este tipo de fenómeno es mejor. Pero también hay alumnos callados.

9. Cuenta alguna experiencia positiva y negativa con algún profesor extranjero durante su enseñanza (si la has vivido).

Negativo: hablar en gallego. Positivo: cuando nosotros expresar que no podemos entender algunas palabras, ellos van a explicarlas.

10. Cuenta alguna experiencia positiva y negativa con algún profesor extranjero a nivel personal (si la has vivido).

La velocidad de responder el correo es demasiado lento. Pero casi todos los profesores son pacientes.

\section{ALUMNA 5}

\section{PREGUNTAS SOBRE LAS TÉCNICAS DE ENSEÑANZA DE LOS PROFESORES EXTRANJEROS DE ESPAÑOL EN CHINA}

- $\quad$ Responde sinceramente a las siguientes preguntas teniendo en cuenta las técnicas de enseñanza de todos los profesores extranjeros de español que hayas tenido a lo largo de tu vida estudiantil.

- En el caso de tener que referirte a alguno de los profesores de español en concreto, lo mantendremos de manera anónima no diciendo ni tu nombre ni el del profesor.

- ¡Gracias por tu ayuda!

1. Las técnicas de enseñanza de los profesores extranjeros, ¿cómo consideras que son? Responde con sinceridad.

Pienso que la mayoría es moderna e interesante, como unas técnicas audiovisuales.

2. ¿Crees que estas técnicas de enseñanza son adecuadas para los alumnos chinos? ¿Sí o no? ¿Por qué?

Sí, porque las técnicas usadas por mis profesores extranjeros me despertaron el interés por español y animaron el entono de clase. 
3. ¿Crees que los profesores extranjeros deberían utilizar las mismas técnicas de enseñanza que los profesores chinos?

Absolutamente no. Porque los profesores chinos, normalmente, usan las técnicas tradicionales, que son muy aburridos.

4. ¿Qué crees que deberían cambiar los profesores extranjeros en sus métodos de enseñanza?

Creo que no. Pero sí necesitan renovar constantemente las técnicas.

5. ¿Qué crees que deberían cambiar los profesores chinos en sus métodos de enseñanza?

Sí. Deben dejar el método de "relleno de pato", lo que solo enseña los conocimientos del libro a través de unas técnicas muy aburridos e ineficaz como memorizar el texto.

6. ¿Crees que las técnicas que utilizan los profesores extranjeros son eficientes a la hora de aprender el español? ¿Qué deberían cambiar o conservar para mantener su eficiencia?

Pienso que en ningún caso las técnicas sean suficientes. Siempre necesitamos renovar las técnicas y conocimientos para alcanzar un resultado mejor. En la etapa de mi estudio de español, una técnica que me impresionó mucho fue estudiar por tareas: el profesor nos exigió grabar un video corto en español. En el proceso de hacer esta tarea, no solo mejoré mi español, sino también logré muchos conocimientos de grabar y editar, los que me benefician mucho.

7. ¿Crees que los profesores extranjeros se adaptan bien a la cultura china dentro del aula? (durante sus clases).

Depende. La mayoría de mis profesores son abiertos a la cultura china: les gustan la comida china, tienen ganas de estudiar el chino y son muy simpáticos a los estudiantes chinos. Pero algunos no, no entiende la cultura china y a los estudiantes tampoco nos gustan sus comportamientos.

8. ¿Qué diferencias crees que hay entre el trato de los profesores chinos y los profesores extranjeros con sus alumnos? ¿Qué aspectos positivos y negativos ves en cada uno de ellos?

En cuanto a la relación entre los profesores chinos y sus alumnos, pienso que es una relación tradicional de profesor-estudiante. Aspecto negativo: hay un sentido de distancia entre ellos.

Al contrario, el trato de los profesores extranjeros con sus alumnos es más simpático, como amigos. Aspecto positivo: a los estudiantes les gustan más las clases de estos profesores.

9. Cuenta alguna experiencia positiva y negativa con algún profesor extranjero durante su enseñanza (si la has vivido). 
Experiencia positiva: en una clase de español, cuando respondí una pregunta difícil, la profesora siempre sentir con la cabeza, esta acción me da coraje de seguir expresar mis pensamientos.

Experiencia negativa: en una clase de inglés, cuando pregunté "What's the deadline of this Project?" Aunque tuve acento, aunque mi pronunciación no fue muy bien, pienso que por lo menos se pude entender esta frase, pero el profesor no intendió comprederlo, sino que mostró un expresión muy perplejo, lo que hizo daño a mi dignidad.

10. Cuenta alguna experiencia positiva y negativa con algún profesor extranjero a nivel personal (si la has vivido).

Positiva: El profesor Alberto me influye mucho en el estudio de español y el hábito de leer. A él le gusta mucho leer, y me animó muchas veces a leer más libros. Además, me trajo a participar a un grupo de lectura. Todas estas acciones me despertaron el interés por leer.

Negativa: Un profesor de mi máster es una persona que falta la capacidad de autocontrol: simpre dijo las palabrotas o hizo unos comportamientos negativos. Una vez, tuve problema con mi tarea grupal, no me dio algunas ayudas sino expresó otra vez unos comportamientos negativos. Pienso que este tipo de persona no es a propósito para la carrera de profesor, porque para ellos, el profesorado solo es un trabajo para vivir, no es una carrera sagrada y feliz.

\section{ALUMNO 6}

\section{PREGUNTAS SOBRE LAS TÉCNICAS DE ENSEÑANZA DE LOS PROFESORES EXTRANJEROS DE ESPAÑOL EN CHINA}

- $\quad$ Responde sinceramente a las siguientes preguntas teniendo en cuenta las técnicas de enseñanza de todos los profesores extranjeros de español que hayas tenido a lo largo de tu vida estudiantil.

- En el caso de tener que referirte a alguno de los profesores de español en concreto, lo mantendremos de manera anónima no diciendo ni tu nombre ni el del profesor.

- ¡Gracias por tu ayuda!

1. Las técnicas de enseñanza de los profesores extranjeros, ¿cómo consideras que son? Responde con sinceridad. 
Generar temas de debate, o por lo menos, un tema sobre el que el estudiante puede aportar su opinión personal con el apoyo de los contenidos audiovisuales. En resumen ,intentar hacer que hable el estudiante sobre un tema interesante. Segundo

2. ¿Crees que estas técnicas de enseñanza son adecuadas para los alumnos chinos? ¿Sí o no? ¿Por qué?

$\mathrm{Si}$, son adecuados, puesto que siempre el rol de los estudiantes chinos ha sido el receptor, por eso, la mayoría de los estudiantes no quieren hablar el castellano frente al público, o ni siquiera saben hablar bien el idioma, aunque tengan un buen nivel escrito. Así que es necesario tener una comunicación bidireccional y que hablen los estudiantes.

3. ¿Crees que los profesores extranjeros deberían utilizar las mismas técnicas de enseñanza que los profesores chinos?

No

4. ¿Qué crees que deberían cambiar los profesores extranjeros en sus métodos de enseñanza?

Hay que forzar un poco a los estudiantes. "Obligar" a ellos a hablar, o a participar.

5. ¿Qué crees que deberían cambiar los profesores chinos en sus métodos de enseñanza?

Preparar la clase para que sea más dinámica.

6. ¿Crees que las técnicas que utilizan los profesores extranjeros son eficientes a la hora de aprender el español? ¿Qué deberían cambiar o conservar para mantener su eficiencia?

No. Siempre hay que animar a los estudiantes chinos, llamar a sus atenciones. Hacer juegos.

7. ¿Crees que los profesores extranjeros se adaptan bien a la cultura china dentro del aula? (durante sus clases).

Bien, pero no suficiente.

8. ¿Qué diferencias crees que hay entre el trato de los profesores chinos y los profesores extranjeros con sus alumnos? ¿Qué aspectos positivos y negativos ves en cada uno de ellos?

La jerarquía existe con los profesores chinos, pero con los extranjeros, ya es más flexible.

9. Cuenta alguna experiencia positiva y negativa con algún profesor extranjero durante su enseñanza (si la has vivido). 
La verdad es que solo tengo las positivas. Durante la clase, podíamos conocer la diferencias culturales, debatimos sobre los temas delicados, así aprendimos el castellano hablando, viendo, escuchando de forma muy natural.

10. Cuenta alguna experiencia positiva y negativa con algún profesor extranjero a nivel personal (si la has vivido).

Mi trato con los profesores extranjeros siempre ha sido de amigos. Hemos pasado muy bien durante los cursos!

\section{ALUMNO 7}

\section{PREGUNTAS SOBRE LAS TÉCNICAS DE ENSEÑANZA DE LOS PROFESORES EXTRANJEROS DE ESPAÑOL EN CHINA}

- $\quad$ Responde sinceramente a las siguientes preguntas teniendo en cuenta las técnicas de enseñanza de todos los profesores extranjeros de español que hayas tenido a lo largo de tu vida estudiantil.

- En el caso de tener que referirte a alguno de los profesores de español en concreto, lo mantendremos de manera anónima no diciendo ni tu nombre ni el del profesor.

- ¡Gracias por tu ayuda!

1. Las técnicas de enseñanza de los profesores extranjeros, ¿cómo consideras que son? Responde con sinceridad.

En mi experiencia, los profesores extranjeros eran buenos en el uso de la dinámica para captar el interés de los estudiantes antes de comenzar la lección a través de minijuegos o vídeos para introducir la lección.

2. ¿Crees que estas técnicas de enseñanza son adecuadas para los alumnos chinos? ¿Sí o no? ¿Por qué?

Creo que esta técnica nos motiva y desarrolla nuestra capacidad de pensar de forma independiente. Aunque hay momentos en los que me siento presionado, el efecto general es positivo.

3. ¿Crees que los profesores extranjeros deberían utilizar las mismas técnicas de enseñanza que los profesores chinos? 
Pienso que las técnicas de enseñanza de los profesores extranjeros deben ser diferentes para que puedan reflejar los puntos fuertes de los profesores extranjeros y la diversidad de la enseñanza.

4. ¿Qué crees que deberían cambiar los profesores extranjeros en sus métodos de enseñanza?

Los estudiantes chinos estamos acostumbrados a recibir conocimientos de forma sistemática. Los profesores chinos son más intrínsecamente lógicos en su enseñanza. Los profesores extranjeros, por el contrario, pueden centrarse más en las competencias adquiridas en la práctica, lo que lleva a veces a una falta de enseñanza sistemática.

5. ¿Qué crees que deberían cambiar los profesores chinos en sus métodos de enseñanza?

Los profesores chinos deberían ser más flexibles a la hora de utilizar el aula para movilizar la creatividad y la motivación de los alumnos, en lugar de limitarse a los programas de enseñanza PPT.

6. ¿Crees que las técnicas que utilizan los profesores extranjeros son eficientes a la hora de aprender el español? ¿Qué deberían cambiar o conservar para mantener su eficiencia?

Creo que es eficaz, cambiar el escenario de la enseñanza o utilizar formatos y tareas novedosas puede, efectivamente, estimular el interés de los alumnos por el aprendizaje del español. Por ejemplo, asignar tareas sobre temas como la microfilmación o la introducción a la comida y la cultura puede hacer que los estudiantes estén más motivados e interesados.

7. ¿Crees que los profesores extranjeros se adaptan bien a la cultura china dentro del aula? (durante sus clases).

Nuestros profesores extranjeros están haciendo un buen trabajo en este sentido, y creo que tienen una cierta comprensión de la cultura china y están tratando de integrarla.

8. ¿Qué diferencias crees que hay entre el trato de los profesores chinos y los profesores extranjeros con sus alumnos? ¿Qué aspectos positivos y negativos ves en cada uno de ellos?

Los profesores extranjeros saben movilizar varios factores positivos para hacer más activo el ambiente de la clase. Y los profesores chinos tienen un claro propósito de enseñanza y son estrictos y estandarizados en la disposición de las lecciones. Creo que los profesores chinos y los extranjeros pueden aprender unos de otros y mejorar juntos su enseñanza.

9. Cuenta alguna experiencia positiva y negativa con algún profesor extranjero durante su enseñanza (si la has vivido).

10. Cuenta alguna experiencia positiva y negativa con algún profesor extranjero a nivel personal (si la has vivido).

Creo que una de las cosas más positivas que experimenté en la clase del profesor extranjero fue que siempre me animaron a responder a las preguntas, incluso si respondía mal. Esto fue muy alentador y me dio más valor para expresar mi opinión. 
ALUMNA 8

\section{PREGUNTAS SOBRE LAS TÉCNICAS DE ENSEÑANZA DE LOS PROFESORES EXTRANJEROS DE ESPAÑOL EN CHINA}

- $\quad$ Responde sinceramente a las siguientes preguntas teniendo en cuenta las técnicas de enseñanza de todos los profesores extranjeros de español que hayas tenido a lo largo de tu vida estudiantil.

- En el caso de tener que referirte a alguno de los profesores de español en concreto, lo mantendremos de manera anónima no diciendo ni tu nombre ni el del profesor.

- ¡Gracias por tu ayuda!

1. Las técnicas de enseñanza de los profesores extranjeros, ¿cómo consideras que son? Responde con sinceridad.

Depende de si el profesor es profesional

2. ¿Crees que estas técnicas de enseñanza son adecuadas para los alumnos chinos? ¿Sí o no? ¿Por qué?

casi. Pero los estudiantes chinos son más adecuados para la práctica repetida. Además, siento que aprender un idioma requiere una práctica repetida

3. ¿Crees que los profesores extranjeros deberían utilizar las mismas técnicas de enseñanza que los profesores chinos?

Los profesores extranjeros no necesitan utilizar las mismas habilidades de enseñanza que los profesores chinos, y cada persona es responsable de diferentes tareas. Los profesores de chino son más adecuados para enseñar gramática, mientras que los profesores extranjeros se centran más en hablar, escuchar y en la cultura.

4. ¿Qué crees que deberían cambiar los profesores extranjeros en sus métodos de enseñanza?

El contenido de la clase es más sustancial

5. ¿Qué crees que deberían cambiar los profesores chinos en sus métodos de enseñanza?

Leer frases, traducir frases, leer textos, traducir textos ... Este método es muy aburrido. Como estudiante universitario, quiero conocer un conocimiento profesional más detallado de la lingüística. 
6. ¿Crees que las técnicas que utilizan los profesores extranjeros son eficientes a la hora de aprender el español? ¿Qué deberían cambiar o conservar para mantener su eficiencia?

eficiente. Utilice el español apropiado en diferentes niveles de estudiantes. Asegúrese de que los estudiantes puedan comprender casi el 50\%

7. ¿Crees que los profesores extranjeros se adaptan bien a la cultura china dentro del aula? (durante sus clases).

sí

8. ¿Qué diferencias crees que hay entre el trato de los profesores chinos y los profesores extranjeros con sus alumnos? ¿Qué aspectos positivos y negativos ves en cada uno de ellos?

La forma en que se trata a los estudiantes depende del estilo de enseñanza de cada profesor y no tiene nada que ver con la nacionalidad. Todo maestro responsable es el mismo.

9. Cuenta alguna experiencia positiva y negativa con algún profesor extranjero durante su enseñanza (si la has vivido).

Positiva: Rico en conocimiento y paciencia

Negativa: Sin plan de enseñanza, sin sentido

Depende todavía de la profesionalidad del profesor.

10. Cuenta alguna experiencia positiva y negativa con algún profesor extranjero a nivel personal (si la has vivido).

Estoy muy feliz de enseñar a un profesor extranjero a jugar Go

ALUMNA 9

\section{PREGUNTAS SOBRE LAS TÉCNICAS DE ENSEÑANZA DE LOS PROFESORES EXTRANJEROS DE ESPAÑOL EN CHINA}

- $\quad$ Responde sinceramente a las siguientes preguntas teniendo en cuenta las técnicas de enseñanza de todos los profesores extranjeros de español que hayas tenido a lo largo de tu vida estudiantil.

- En el caso de tener que referirte a alguno de los profesores de español en concreto, lo mantendremos de manera anónima no diciendo ni tu nombre ni el del profesor.

- ¡Gracias por tu ayuda! 
1. Las técnicas de enseñanza de los profesores extranjeros, ¿cómo consideras que son? Responde con sinceridad.

Depende de si el profesor es profesional

2. ¿Crees que estas técnicas de enseñanza son adecuadas para los alumnos chinos? ¿Sí o no? ¿Por qué?

casi. Pero los estudiantes chinos son más adecuados para la práctica repetida. Además, siento que aprender un idioma requiere una práctica repetida

3. ¿Crees que los profesores extranjeros deberían utilizar las mismas técnicas de enseñanza que los profesores chinos?

Los profesores extranjeros no necesitan utilizar las mismas habilidades de enseñanza que los profesores chinos, y cada persona es responsable de diferentes tareas. Los profesores de chino son más adecuados para enseñar gramática, mientras que los profesores extranjeros se centran más en hablar, escuchar y en la cultura.

4. ¿Qué crees que deberían cambiar los profesores extranjeros en sus métodos de enseñanza?

El contenido de la clase es más sustancial

5. ¿Qué crees que deberían cambiar los profesores chinos en sus métodos de enseñanza?

Leer frases, traducir frases, leer textos, traducir textos ... Este método es muy aburrido.

Como estudiante universitario, quiero conocer un conocimiento profesional más detallado de la lingüística.

6. ¿Crees que las técnicas que utilizan los profesores extranjeros son eficientes a la hora de aprender el español? ¿Qué deberían cambiar o conservar para mantener su eficiencia?

eficiente. Utilice el español apropiado en diferentes niveles de estudiantes. Asegúrese de que los estudiantes puedan comprender casi el $50 \%$

7. ¿Crees que los profesores extranjeros se adaptan bien a la cultura china dentro del aula? (durante sus clases).

sí

8. ¿Qué diferencias crees que hay entre el trato de los profesores chinos y los profesores extranjeros con sus alumnos? ¿Qué aspectos positivos y negativos ves en cada uno de ellos?

La forma en que se trata a los estudiantes depende del estilo de enseñanza de cada profesor y no tiene nada que ver con la nacionalidad. Todo maestro responsable es el mismo.

9. Cuenta alguna experiencia positiva y negativa con algún profesor extranjero durante su enseñanza (si la has vivido).

Positiva: Rico en conocimiento y paciencia

Negativa: Sin plan de enseñanza, sin sentido

Depende todavía de la profesionalidad del profesor. 
10. Cuenta alguna experiencia positiva y negativa con algún profesor extranjero a nivel personal (si la has vivido).

Estoy muy feliz de enseñar a un profesor extranjero a jugar Go

ALUMNA 10

\section{PREGUNTAS SOBRE LAS TÉCNICAS DE ENSEÑANZA DE LOS PROFESORES EXTRANJEROS DE ESPAÑOL EN CHINA}

- $\quad$ Responde sinceramente a las siguientes preguntas teniendo en cuenta las técnicas de enseñanza de todos los profesores extranjeros de español que hayas tenido a lo largo de tu vida estudiantil.

- En el caso de tener que referirte a alguno de los profesores de español en concreto, lo mantendremos de manera anónima no diciendo ni tu nombre ni el del profesor.

- ¡Gracias por tu ayuda!

1. Las técnicas de enseñanza de los profesores extranjeros, ¿cómo consideras que son? Responde con sinceridad.

1) Clases magistrales: la calidad depende de cada profesor y puede variar muchísimo.

2) Lectura comentada: lo más aburrido. Eficacia nula.

3) Aprendizaje cooperativo: un dolor de cabeza. Parece que uno debería haber salvado el mundo para poder toparse con algún que otro miembro con cierto sentido de responsabilidad en los trabajos de grupo.

4) Exposiciones por parte de los alumnos: lo mismo con las clases magistrales.

5) Actividades experimentales: la innovación siempre es bienvenida.

2. ¿Crees que estas técnicas de enseñanza son adecuadas para los alumnos chinos? ¿Sí o no? ¿Por qué?

Sí, si se combina estas técnicas bien, porque así se cuidan tanto el aspecto más orientado a los examenes como las necesidades reales de los alumnos.

3. ¿Crees que los profesores extranjeros deberían utilizar las mismas técnicas de enseñanza que los profesores chinos?

Si se está refiriendo a las técnicas mayortariamente expositivas, por supuesto que no.

4. ¿Qué crees que deberían cambiar los profesores extranjeros en sus métodos de enseñanza? 
No sabría decir un método concreto, pero sí que me parece muy importante hacer participar a más alumnos. Cuando uno se interesa por el tema, hablará en clase seguro.

5. ¿Qué crees que deberían cambiar los profesores chinos en sus métodos de enseñanza?

Basándome en los métodos de enseñanza que se adoptan en mi uni:

Que haya más interacciones. Que hagan diapositivas por cuenta propia. Que pongan fuentes o referencias. Que los libros de texto «Español Moderno» no lo es todo (de hecho, deja mucho que desear). Que hablen español en clase.

6. ¿Crees que las técnicas que utilizan los profesores extranjeros son eficientes a la hora de aprender el español? ¿Qué deberían cambiar o conservar para mantener su eficiencia?

1) No creo que sea necesario rebajar el nivel de la lengua solo para adaptase al nivel de los alumnos, aunque sean clases para principiantes.

2) Personalmente, me parece muy poco las tareas que se les asignan a los alumnos chinos y me gustaría que se pudiera poner más lecturas. Al menos se puede hacer alguna mención de los recursos relacionados con el tema en cuestión.

3) Curiosamente, los profesores extranjeros raras veces acaban el temario que tenía preparado...

7. ¿Crees que los profesores extranjeros se adaptan bien a la cultura china dentro del aula? (durante sus clases).

Sí, pues las aulas tampoco dan mucho de sí.

8. ¿Qué diferencias crees que hay entre el trato de los profesores chinos y los profesores extranjeros con sus alumnos? ¿Qué aspectos positivos y negativos ves en cada uno de ellos?

1) Los profesores chino hablan del mercado laboral y comparten cosas de este tipo. Las relaciones entre ellos y los alumnos pueden ser más «duraderas», bien por la similitud sociocultural, bien por el intento de construir «guanxi» por parte de algunos alumnos.

2) Creo que generalmente los profesores chinos son más serios en clase y el ambiente en el aula suele ser bastante sofocante.

9. Cuenta alguna experiencia positiva y negativa con algún profesor extranjero durante su enseñanza (si la has vivido).

1) Positiva:

Me ha gustado mucho las clases de A y D porque dieron clases con humor y hacen actividades interesantes (doblaje, cortometraje, entre otros). Se aprenden y se divierten. ;) La profa M. (de Argentina) incorporó muchas experiencias personales a sus clases. Me conmueve mucho su autenticidad y franqueza. 
2) Negativa:

Un tal profe $\mathrm{G}$ que no conocía muy bien lo que estaba enseñando.

Otro profe $\mathrm{X}$ al que nadie le escuchaba en clase. Pero bueno, algo sí que nos enseñó: el poder del aburrimiento.

10. Cuenta alguna experiencia positiva y negativa con algún profesor extranjero a nivel personal (si la has vivido).

1) Positiva:

Me lo pasé muy bien en Madrid :) ¡Gracias por invitarme! Me parece muy bonito el contacto que estamos teniendo.

2) Negativa:

$\mathrm{n} / \mathrm{p}$

6 de julio de 2021 